\title{
Poor Schedule Management Leads to Discontinuity of Medical Attendance among Patients Infected with HIV
}

\author{
Fumiko Kagiura1 (1), Megumi Shimada², Masayuki Kakehashi1 \\ ${ }^{1}$ Graduate School of Biomedical and Health Sciences, Hiroshima University, Hiroshima, Japan \\ ${ }^{2}$ Graduate School of Human Health Sciences, Tokyo Metropolitan University, Tokyo, Japan \\ Email: fumiko5@hiroshima-u.ac.jp
}

How to cite this paper: Kagiura, F., Shimada, M. and Kakehashi, M. (2019) Poor Schedule Management Leads to Discontinuity of Medical Attendance among Patients Infected with HIV. Health, 11, 277-288. https://doi.org/10.4236/health.2019.113024

Received: January 31, 2019

Accepted: March 1, 2019

Published: March 4, 2019

Copyright () 2019 by author(s) and Scientific Research Publishing Inc. This work is licensed under the Creative Commons Attribution International License (CC BY 4.0).

http://creativecommons.org/licenses/by/4.0/

\section{c) (i) Open Access}

\begin{abstract}
Dropout from medical attendance is a well-recognized issue among patients with human immunodeficiency virus (HIV) infection. We interviewed 23 HIV-positive patients and used text mining methods to analyse the risk factors for dropout. Fifteen patients continued medical attendance and eight patients dropped out of medical attendance. Categories were extracted from the interview data of the patients who continued medical attendance (i.e., the continuity group) and the patients who dropped out of medical care (i.e., the discontinuity group). Categories of the continuity group included needing to take a day off for medical attendance, scheduling each appointment, writing down medical appointments, being grateful for the medical care, and 12 additional categories. Categories of discontinuity group included forgetting the dates of medical appointments, not needing to get a day off for medical attendance, allowing aid for medical care to expire, and 10 additional categories. The discontinuity group had poorer schedule management than the continuity group, which caused them to forget their next medical appointments and delay the renewal of aid for medical care. Thus, medical staff may be able to prevent dropouts by ensuring that patients record the dates of their medical appointments.
\end{abstract}

\section{Keywords}

Medical Attendance, Human Immunodeficiency Virus, Text Mining,

Face-to-Face Interview

\section{Introduction}

Discontinuity in medical care by patients infected with human immunodefi- 
ciency virus (HIV) is one of the most notable issues encountered by medical staff around the world. Discontinuing medical care (i.e., combined antiretroviral therapy) may lead to increases in HIV RNA titers [1] and will, subsequently, increase the rate of mortality [2] [3].

Many studies have tried to clarify factors that are associated with the discontinuation of medical care among patients infected with HIV, and most have been reported in the US or in African regions where medical insurance systems are insufficient. Based on demographic and clinical data, factors that were shown to be associated with discontinuation of medical care were young patients [4] [5] [6], not having started antiretroviral therapy [5] [7] [8], and not having or using health insurance, Medicare, or Medicaid (in which the latter two were specific to US citizens) [9] [10].

Qualitative data from interviews have provided important insights for the prevention of missed medical care. Flores et al. [11] showed that cultural, interpersonal, and social factors were related to the discontinuation of medical care. Some difficulties in continuing medical care brought up by patients include issues with their relationship with the medical staff, issues in the care system, lack of support from their family, inconvenient transport to the hospital, and temporal and economic restrictions. Interventions, such as improvement in the attitude of the medical staff towards the patients [12] and improvement in medical services [13], were reported to be effective for continuing medical care.

Factors that cause missed medical appointments differ depending on culture and health insurance systems. In Japan, since all citizens are obligated to have health insurance, the medical fees of HIV patients are financially supported. Furthermore, Japan has an efficient public transportation network. Despite these circumstances, some reports [14] [15] [16] have shown that approximately $5 \%$ to $10 \%$ of patients who are infected with HIV discontinue medical care in Japan. In this study, we clarified factors that led to the discontinuation of medical care among HIV patients in Japan by analyzing data from interviews.

\section{Methods}

\subsection{Recruitment and Data Collection}

Japanese adults aged 20 years and older who were diagnosed with HIV for over six months prior to the interview were recruited from three hospitals in Japan. The exclusion criteria were people who did not speak Japanese or who were infected with HIV via blood products. Two researchers with experience providing HIV care for over 5 years conducted the semi-structured face-to-face interviews in a private room before or after the participants met their HIV doctors at the hospitals between February 2016 and June 2017. In the interviews, they focused on clarifying the thoughts and behavior of patients regarding medical care. Additionally, the patients were asked regarding out-of-pocket medical expenditures per medical appointment in order to collect economic data. All interviews were audio-recorded by an IC recorder and transcribed by professionals. Informed 
consent was obtained from the patients prior to participation in the study.

Sociodemographic and clinical data were collected from medical records (e.g., age, sex, HIV infection risk factors, time since diagnosis, CD4 cell count, HIV-RNA titers, and antiretroviral therapy).

\subsection{Methods of Analysis}

Following the interviews in which the participants disclosed their behavior and thoughts after their diagnosis with HIV, the transcribed data were analyzed. Transcribed data for patients who discontinued medical care but were thinking of restarting it were excluded. After dividing the descriptions by topics, the data were analyzed by a text-mining approach with SPSS Text Analytics for Surveys ver. 4.0.1. In the first step of the text-mining approach, different words with the same meaning were merged into a single word. For example, the words "nurse", "nurses", "coordinator nurse", and "coordinator" were merged into the single word "nurse". Emotions related to medical care were important factors and were analyzed using Sentiments Analysis of SPSS Text Analytics, which is able to collect expressions of similar emotions even if they are described by different words. At the end of the text-mining approach, the data were transformed into binary matrix data. Descriptions of the matrix data were analyzed by hierarchical cluster analysis (method: ward) using R version 3.3.1 to create groups with similar content.

The names of each group were given based on the descriptions and frequency of the words. The process of analysis is shown in Figure 1.

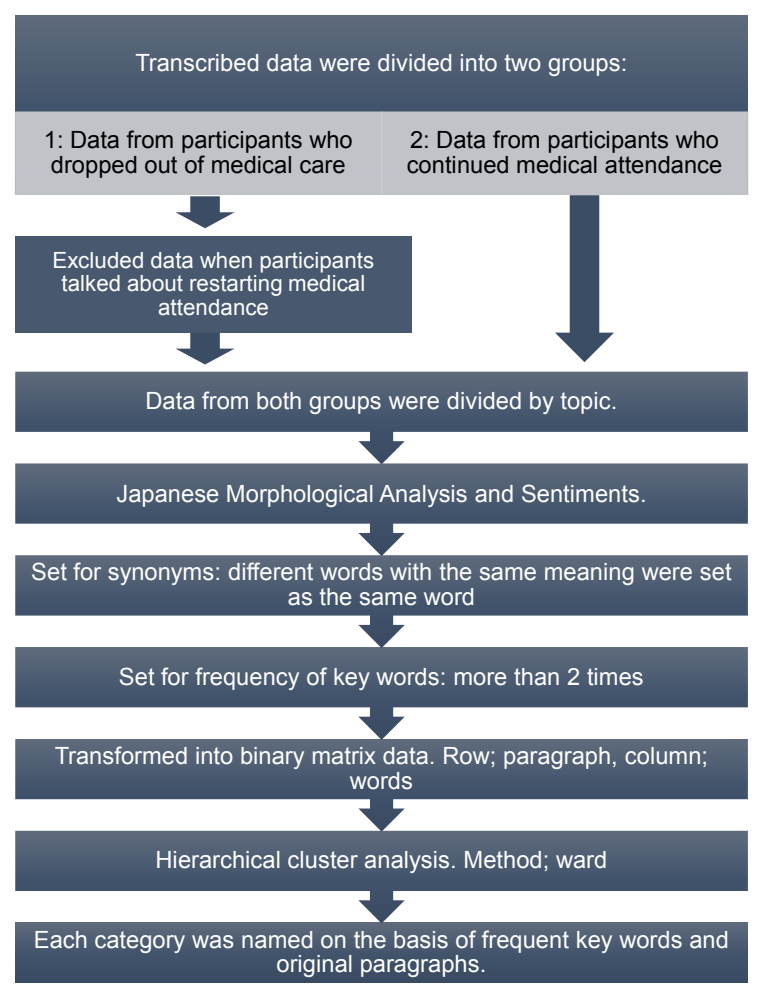

Figure 1. Process of analysis. 


\subsection{Ethical Considerations}

This study was approved by the Ethical Committee for Epidemiology at the Hiroshima University (No. E-226).

\section{Results}

\subsection{Participants}

A total of 23 participants were interviewed: 15 had continuous medical care (continuity group), and 8 missed a medical appointment at least once and continued for less than 6 months (discontinuity group). The average interview time for the continuity and discontinuity group was 58.2 and $58.4 \mathrm{~min}$, respectively. The average age of the participants in the continuity and discontinuity groups was 47.7 and 39.0 years old, respectively. In this study, 10 and 6 participants in the continuity and discontinuity groups shared the most frequent HIV infection risk factor of men who have sex with men (MSM). Additional demographic and clinical characteristics are shown in Table 1.

\subsection{Categories Obtained from the Interview Data of Patients in the Continuity Group}

Based on the results of the cluster analysis, 16 categories were obtained from the data of participants in the continuity group. Table 2 shows the category names and frequently used words for each category. The categories are as follows:

Table 1. Demographic and clinical characteristics.

\begin{tabular}{|c|c|c|}
\hline & Continuity group & Discontinuity group \\
\hline & $(\mathrm{N}=15)$ & $(\mathrm{N}=8)$ \\
\hline Average time of interview (mins, SD) & $58.2(17.2)$ & $58.4(0.2)$ \\
\hline Average age (years, SD) & $47.7(14.2)$ & $39.0(9.5)$ \\
\hline \multicolumn{3}{|l|}{ Sex } \\
\hline Male & 12 & 6 \\
\hline Female & 3 & 2 \\
\hline
\end{tabular}

HIV infection risk factors

\begin{tabular}{lcc} 
MSM & 10 & 6 \\
Heterosexual & 5 & 2 \\
IDU & 0 & 0 \\
\hline
\end{tabular}

Time since diagnosis (years)

$\begin{array}{lcc}<2 & 2 & 1 \\ 2-10 & 10 & 3 \\ 11-20 & 2 & 4 \\ >20 & 1 & 0\end{array}$

CD4 cell count $(/ \mu \mathrm{l})$ 


\section{Continued}

\begin{tabular}{|c|c|c|}
\hline $401-700$ & 7 & 6 \\
\hline$>701$ & 5 & 2 \\
\hline \multicolumn{3}{|l|}{ HIV-RNA (copies/ ml) } \\
\hline$<200$ & 15 & 6 \\
\hline $201-1000$ & 0 & 0 \\
\hline$>1001$ & 5 & 2 \\
\hline
\end{tabular}

Receiving antiretroviral therapy

$\begin{array}{lcc}\text { Yes } & 15 & 8 \\ \text { No } & 0 & 1\end{array}$

Out-of-pocket medical expenditures (yen/visit)

$\begin{array}{lll}0-1000 & 7 & 2 \\ 1001-10,000 & 1 & 4 \\ 10,001-20,000 & 7 & 2\end{array}$

Table 2. Categories of the continuity group and frequently used words.

\begin{tabular}{|c|c|c|}
\hline & Category names & Three most frequently used words \\
\hline 1 & Managing own health condition & $\begin{array}{l}\text { myself, medical attendance, hospital }{ }^{*} \text {, } \\
\text { blood test }^{*}\end{array}$ \\
\hline 2 & Concealing HIV status from others & myself, other person, uncomfortable \\
\hline 3 & $\begin{array}{l}\text { Decision to disclose or conceal HIV status from } \\
\text { family }\end{array}$ & family, HIV, myself \\
\hline 4 & $\begin{array}{l}\text { Feeling ill or shocked after being diagnosed with } \\
\text { HIV }\end{array}$ & first, HIV, medical attendance \\
\hline 5 & Taking a day off for medical care & job, day off, medical attendance \\
\hline 6 & Scheduling appointments & $\begin{array}{l}\text { planning except medical attendance, } \\
\text { medical attendance, myself }\end{array}$ \\
\hline 7 & Making records for future medical appointments & medical attendance, next, hospital \\
\hline 8 & $\begin{array}{l}\text { Checking the reservation slip to confirm the } \\
\text { appointment day }\end{array}$ & medical attendance, anxious, HIV \\
\hline 9 & $\begin{array}{l}\text { Gratitude for being able to receive financial aid for } \\
\text { HIV medical care }\end{array}$ & $\begin{array}{l}\text { social security program } \\
\text { medical burden of } \operatorname{cost}^{*} \text {, medication }\end{array}$ \\
\hline 10 & Receiving prescriptions & taking medicine, myself, medication \\
\hline 11 & Taking medicine & taking medicine, medication, talk \\
\hline 12 & Managing health for the sake of significant others & $\begin{array}{l}\text { myself, health condition, medication }{ }^{*} \text {, } \\
\text { pleasure }^{\star}\end{array}$ \\
\hline 13 & $\begin{array}{l}\text { Feeling at ease with medication and staying in the } \\
\text { outpatient ward }\end{array}$ & medication, ease, first ${ }^{*}$, myself ${ }^{*}$ \\
\hline 14 & Enjoying life and medical care & myself, feeling, pleasure \\
\hline 15 & Trust in the medical staff & primary doctor, nurse, hospital \\
\hline 16 & Relationship with and trust in the primary doctor & $\begin{array}{l}\text { primary doctor, medical attendance, } \\
\text { pleasure }\end{array}$ \\
\hline
\end{tabular}

${ }^{*}$ Words of the same frequency. 
1) Managing own health condition: Participants discussed managing health conditions by taking medicine and receiving medical care.

2) Concealing HIV status from others: Participants discussed revealing their HIV status to others or their decision to tell none since it may negatively affect their social relationships.

3) Decision to disclose or conceal HIV status from family: Participants discussed their relationship with their families after having told them their HIV status. For some, the family members became supportive after knowing their HIV status. However, others decided to never reveal their HIV status.

4) Feeling ill or shocked after being diagnosed with HIV: Participants discussed their mental and physical condition after knowing their HIV status wherein they experienced worsening health conditions, depression, or the inability to process their thoughts regarding their diagnosis.

5) Taking days off for medical care: Participants discussed the effect of receiving medical care on their jobs. Some participants did not have jobs, but others would apply to take a day off work in order to attend their medical appointment.

6) Scheduling appointments: Participants discussed managing their schedule for medical care for which they were able to plan well.

7) Making records for future medical appointments: Participants discussed making reminders for medical appointments. After having set the date, they would make note of their next medical appointment in booklets, calendar apps, or paper calendars.

8) Checking the reservation slip to confirm the appointment day: Participants discussed their worries regarding their medical care such as meeting others in the hospital and making sure they have the right appointment date.

9) Gratitude for being able to receive financial aid for HIV medical care: Participants discussed feeling grateful to be able to receive financial aid to reduce fees associated with their HIV medical care.

10) Receiving prescriptions: Participants discussed receiving medication (i.e., antiretroviral drugs) from the hospital.

11) Taking medicine: Participants discussed taking antiretroviral drugs and talking to others regarding it.

12) Managing health for the sake of significant others: Participants discussed their thoughts on health management in which they felt compelled to manage their health condition since their significant other paid close attention to their health.

13) Feeling at ease with medication and staying in the outpatient ward: Participants discussed feeling at ease when taking antiretroviral drugs or being in the hospital.

14) Enjoying life and medical care: Participants discussed their enjoyments in life. They felt pleasure while they were in the hospital doing their hobby or in friendship.

15) Trust in the medical staff: Participants discussed their relationship with 
the medical staff in which they had good rapport with their primary doctor or nurses at the hospital.

16) Relationship with and trust in the primary doctor: Participants discussed having conversations with their primary doctor or having trust in their primary doctor.

\subsection{Categories Obtained from the Interview Data of Patients Who Discontinued Medical Care}

Based on the results of the cluster analysis, 13 categories were obtained from the data of participants who discontinued medical care. Table 3 shows the category names and frequently used words in each category. The categories are as follows:

1) Feeling ill or shocked after being diagnosed with HIV: Participants discussed their feelings after diagnosis in which they felt ill upon hearing their HIV status and shocked when they were diagnosed with HIV. Some were already in poor health condition prior to their diagnosis.

2) Self-disgust at their HIV status: Participants discussed feeling disgusted at their own HIV status.

3) Difficulties with social relationships: Participants discussed changes in social relationships due to troubles with friends or their depression. They felt there were fewer opportunities to meet friends prior to discontinuing medical care.

4) Not having started antiretroviral drugs: Participants discussed not taking

Table 3. Categories of the discontinuity group and frequently used words.

\begin{tabular}{|c|c|c|}
\hline & Category names & Three most frequently used words \\
\hline 1 & $\begin{array}{l}\text { Feeling ill or shocked after being diagnosed with } \\
\text { HIV }\end{array}$ & HIV, first, tell \\
\hline 2 & Self-disgust at their HIV status & HIV, myself, nurse ${ }^{\star}$, uncomfortable ${ }^{*}$ \\
\hline 3 & Difficulties with social relationships & friend, HIV, hospital \\
\hline 4 & Not having started antiretroviral drugs & $\begin{array}{l}\text { medication, take medicine, medical } \\
\text { attendance }\end{array}$ \\
\hline 5 & $\begin{array}{l}\text { Decision to disclose or conceal their HIV status } \\
\text { from family }\end{array}$ & HIV, first, family ${ }^{\star}$, tell ${ }^{\star}$ \\
\hline 6 & Losing faith in the doctor & medication, take medicine, primary doctor \\
\hline 7 & Keeping the reservation slip & medical attendance, next, reservation slip \\
\hline 8 & Forgetting the dates of the medical appointment & medical attendance, hospital, forget \\
\hline 9 & $\begin{array}{l}\text { Not requiring taking days off work to attend } \\
\text { medical appointments }\end{array}$ & job, medical attendance, day off \\
\hline 10 & Having other appointments in addition to work & $\begin{array}{l}\text { counselling, myself }{ }^{*} \text {, plans except for work } \\
\text { job }^{*}\end{array}$ \\
\hline 11 & Losing support from family members & hospital, myself, family \\
\hline 12 & Stress from personal relationship & uncomfortable, meet, medical attendance \\
\hline 13 & $\begin{array}{l}\text { Delaying or failing to renew registration for } \\
\text { financial aid }\end{array}$ & $\begin{array}{l}\text { social security program, myself } f^{*}, \\
\text { document }^{*} \text {, uncomfortable*, burden of } \\
\text { medical cost }^{*}\end{array}$ \\
\hline
\end{tabular}

${ }^{*}$ Words of the same frequency. 
medication either because they did not start receiving antiretroviral therapy or the therapy had a bad side effect.

5) Decision to disclose or conceal their HIV status from family: Participants discussed, when they were in good health, what steps were taken after their HIV diagnosis. While some decided to disclose their HIV status to their family, others thought it was unnecessary.

6) Losing faith in the doctor: Participants discussed having, at first, trust in their primary doctor before gradually losing it over time.

7) Keeping the reservation slip: Participants discussed keeping the reservation slip. They did not set a reminder for their appointment on their phone even though they kept the reservation slip that they received at the hospital.

8) Forgetting the dates of the medical appointment: Participants discussed forgetting the medical appointment dates.

9) Not requiring taking days off work to attend medical appointments: Participants discussed how it was unnecessary to take a day off work to attend their medical appointments since they either went to the hospital after a night shift or during their day off on the weekday.

10) Having other appointments in addition to work: Participants discussed their daily life schedule with plans other than work (e.g., counselling or hobbies).

11) Losing support from family members: Participants discussed discontinuing medical care after losing support from family members to visit hospitals.

12) Stress from personal relationship: Participants discussed feeling stressed from personal relationships.

13) Delaying or failing to renew registration for financial aid: Participants discussed delaying the renewal procedure that resulted in the expiry of the registration for financial aid.

\subsection{Some Common Categories}

There were 2 common categories shared by both groups: "deciding to disclose or conceal HIV status from family members" and "feeling ill or shocked after being diagnosed with HIV". The remaining categories were different between both groups.

\section{Discussion}

We analysed the interview data of participants who continued or discontinued medical care using a text-mining method, and, as a result, obtained 16 and 13 categories for the former and latter groups, respectively. Although there were some categories in common between both groups, most were different.

Compared to the continuity group, the ability to manage schedules seemed to be weaker in the discontinuity group. Based on the interviews, the discontinuity group often forgot the date of their medical appointments. In contrast, the continuity group recorded the date of appointment, applied for leave at work, and also mentioned gratitude for being able to receive medical financial aid. They 
also recorded the date of their next appointment in a scheduling application on their mobile phones, agendas, or calendars in order to not forget the appointment date. In contrast, the participants in the discontinuity group did not have to apply for leave at work to attend their medical appointments because they either worked night shifts or had days off on a weekday. Despite these favourable situations, they were more prone to forgetting their appointments since less attention was given to the date. Participants of the continuity group expressed gratitude for medical financial aid; however, in contrast, participants in the discontinuity group were not able to meet the deadline for the financial aid renewal procedures that led to the loss of their designated status and caused them to discontinue medical care. Financial aid for HIV medical care provided in Japan significantly reduces medical and examination expenses. The remaining fees are paid by the patient but are determined by the income of the previous year. Therefore, patients are required to renew their certificates every year [17] by filling out application forms, receiving the medical certificates, and then submitting these documents to the municipal government. However, some patients may not have the proper knowledge for these procedures. The medical staff caring for HIV patients may not check to see whether a reminder for a medical appointment was made or not. Since inquiring about a patient's schedule management can be performed easily, it may help alert the medical staff whether a patient is at risk for discontinuing medical care and allow them to consider strategies for intervention.

In comparison with the continuity group, the motivation to receive medical care is lower in the discontinuity group. In addition, whether the patient is undergoing antiretroviral therapy or not seems to have considerable influence in continuing medical care. It has been reported that the discontinuation of medical care is related to the absence of antiretroviral therapy [5] [7] [8] and is consistent with our results. Patients who start antiretroviral therapy cannot continue without ongoing medical care. Therefore, antiretroviral therapy promotes the continuation of medical care. Consequently, the continuity group had more discussions regarding managing their own health than the discontinuity group. Furthermore, differences in handling the reservation slip also showed the differences in motivation levels for receiving medical care. Patients who visit hospitals in Japan usually receive a reservation slip on which information regarding the name of the clinical department, date, and hour of the next visit is stated. The continuity group discussed having checked the slip before their appointment even if they had a reminder. In contrast, the discontinuity group only discussed keeping the reservation slip. The reservation slip may not be effective in preventing the discontinuation of medical care unless the patients themselves have sufficient motivation to attend their appointments.

While the continuity group had good relationships with their doctor, the discontinuity group eventually lost trust in the medical staff. Good relationships with the medical staff are important in continuing medical care [18] [19] [20] [21]. The discontinuity group also discussed having stress with personal rela- 
tionships. Discontinuing medical care is likely caused by depression [4] [22] or illegal drug use [16] [22]. Sinha [23] [24] suggested that stress can also lead to illegal drug use. There are reports that stress from social relationships can lead to depression [25] [26] and may also lead to the discontinuation in medical care.

Two common categories were obtained from both groups. Of these, one category was "feeling ill or shocked after being diagnosed with HIV". Feeling ill or shocked did not seem to be a determinate factor in continuing medical care since this category was observed in both the continuity and discontinuity groups. The other category was the "decision to disclose or conceal HIV status from family members". This may also not have an effect as to whether the patient continues medical care since most patients would have these thoughts if they were diagnosed with HIV.

There are some limitations to this study. The small sample size in the short duration may be insufficient to represent all the Japanese patients who are infected with HIV. A larger list of categories could be created if more patients are enrolled in future studies. Furthermore, although we analysed the interview data by text-mining method for reproducibility, complex and meaningful relationships between the obtained categories may not have been clarified.

Although there were some limitations, the result of this study indicates the preventive way to the drop-out from medical care among Japanese adults with HIV. The medical staff should pay attention if the patients record the date of next appointment with HIV doctors, and especially to the patients with less motivation (e.g., patients who have not started antiretroviral therapy). It is helpful to decrease the drop-out rate of patients with HIV from medical care.

\section{Conclusion}

Through a text-mining method and cluster analysis, this study analysed interview data from 23 patients who were infected with HIV in which the main topics were their feelings and behaviour regarding medical care. By comparing the categories from both the continuity and discontinuity groups, there were large differences in behaviour. Patients who did not schedule their next medical appointment were more likely to discontinue medical care. These results may help medical staff in preventing HIV patients from missing their medical appointments.

\section{Acknowledgements}

This work was supported by the Health Care Science Institute under Grant 2015. The funder had no role in the study design, data collection and analysis, decision to publish, or preparation of the manuscript. The authors declare no conflicts of interest.

\section{Conflicts of Interest}

The authors declare no conflicts of interest regarding the publication of this paper. 


\section{References}

[1] Berg, M.B., Safren, S.A., Mimiaga, M.J., Grasso, C., Boswell, S. and Mayer, K.H. (2005) Nonadherence to Medical Appointments Is Associated with Increased Plasma HIV RNA and Decreased CD4 Cell Counts in a Community-Based HIV Primary Care Clinic. AIDS Care, 17, 902-907. https://doi.org/10.1080/09540120500101658

[2] Giordano, T.P., Gifford, A.L., White, A.C., Suarez-Almazor, M.E., Rabeneck, L., Hartman, C., et al. (2007) Retention in Care: A Challenge to Survival with HIV Infection. Clinical Infectious Diseases, 44, 1493-1499. https://doi.org/10.1086/516778

[3] Mugavero, M.J., Lin, H.Y., Willig, J.H., Westfall, A.O., Ulett, K.B., Routman, J.S., et al. (2009) Missed Visits and Mortality among Patients Establishing Initial Outpatient HIV Treatment. Clinical Infectious Diseases, 48, 248-256. https://doi.org/10.1086/595705

[4] Bofill, L., Waldrop-Valverde, D., Metsch, L., Pereyra, M. and Kolber, M.A. (2011) Demographic and Psychosocial Factors Associated with Appointment Attendance among HIV-Positive Outpatients. AIDS Care, 23, 1219-1225. https://doi.org/10.1080/09540121.2011.555743

[5] Crawford, T.N. (2015) Examining the Relationship between Multiple Comorbidities and Retention in HIV Medical Care: A Retrospective Analysis. AIDS Care, 27, 892-899. https://doi.org/10.1080/09540121.2015.1009361

[6] Saberi, P. and Johnson, M.O. (2015) Moving toward a Novel and Comprehensive Behavioral Composite of Engagement in HIV Care. AIDS Care, 27, 660-664.

https://doi.org/10.1080/09540121.2014.986052

[7] Hermanides, H.S., Holman, R., Gras, L., Winkel, C.N., Gerstenbluth, I., de Wolf, F., et al. (2013) High Incidence of Intermittent Care in HIV-1-Infected Patients in Curacao before and after Starting cART. AIDS Care, 25, 1411-1417. https://doi.org/10.1080/09540121.2013.772276

[8] Blutinger, E.J., Solomon, S., Srikrishnan, A.K., Thamburaj, E., Kumarasamy, N., Balakrishnan, P., et al. (2014) Dropout from Care among HIV-Infected Patients Enrolled in Care at a Tertiary HIV Care Center in Chennai, India. AIDS Care, 26, 1500-1505. https://doi.org/10.1080/09540121.2014.934654

[9] Shapiro, M.F., Morton, S.C., McCaffrey, D.F., Senterfitt, J.W., Fleishman, J.A., Perlman, J.F., et al. (1999) Variations in the Care of HIV-Infected Adults in the United States: Results from the HIV Cost and Services Utilization Study. JAMA, 281, 2305-2315. https://doi.org/10.1001/jama.281.24.2305

[10] Andersen, R., Bozzette, S., Shapiro, M., St. Clair, P., Morton, S., Crystal, S., et al. (2000) Access of Vulnerable Groups to Antiretroviral Therapy among Persons in Care for HIV Disease in the United States. HCSUS Consortium. HIV Cost and Services Utilization Study. Health Services Research, 35, 389-416. https://www.ncbi.nlm.nih.gov/pmc/articles/PMC1089126/

[11] Flores, D., Leblanc, N. and Barroso, J. (2016) Enroling and Retaining Human Immunodeficiency Virus (HIV) Patients in Their Care: A Metasynthesis of Qualitative Studies. International Journal of Nursing Studies, 62, 126-136.

[12] Gardner, L.I., Marks, G., Shahani, L., Giordano, T.P., Wilson, T.E., Drainoni, M.L., et al. (2016) Assessing Efficacy of a Retention-in-Care Intervention among HIV Patients with Depression, Anxiety, Heavy Alcohol Consumption and Illicit Drug Use. Aids, 30, 1111-1119. https://doi.org/10.1097/QAD.0000000000001019

[13] Davila, J.A., Miertschin, N., Sansgiry, S., Schwarzwald, H., Henley, C. and Giordano, T.P. (2013) Centralization of HIV Services in HIV-Positive African-American and Hispanic Youth Improves Retention in Care. AIDS Care, 25, 202-206. 
https://doi.org/10.1080/09540121.2012.689811

[14] Ikeda, K. and Kawamura, S. (2008) The Research about Related Factors to Continuity of Medical Attendance among Patients Were Diagnosed as HIV/AIDS. Journal of Japan Academy of Human Care Science, 1, 23-31.

[15] Tominari, S., Nakakura, T., Yasuo, T., Yamanaka, K., Takahashi, Y., Shirasaka, T., et al. (2013) Implementation of Mental Health Service Has an Impact on Retention in HIV Care: A Nested Case-Control Study in a Japanese HIV Care Facility. PLoS ONE, 8, e69603. https://doi.org/10.1371/journal.pone.0069603

[16] Nishijima, T., Gatanaga, H., Komatsu, H., Takano, M., Ogane, M., Ikeda, K., et al. (2013) Illicit Drug Use Is a Significant Risk Factor for Loss to Follow up in Patients with HIV-1 Infection at a Large Urban HIV Clinic in Tokyo. PLoS ONE, 8, e72310. https://doi.org/10.1371/journal.pone.0072310

[17] Ministry of Health Law, Ministry of Health, Labor and Welfare (2018) The Aids for Handicapped People. The Government of Japan.

https://www.mhlw.go.jp/stf/seisakunitsuite/bunya/hukushi_kaigo/shougaishahukus hi/jiritsu/index.html

[18] Buchberg, M.K., Fletcher, F.E., Vidrine, D.J., Levison, J., Peters, M.Y., Hardwicke, R., et al. (2015) A Mixed-Methods Approach to Understanding Barriers to Postpartum Retention in Care among Low-Income, HIV-Infected Women. AIDS Patient Care STDS, 29, 126-132.

[19] Yehia, B.R., French, B., Fleishman, J.A., Metlay, J.P., Berry, S.A., Korthuis, P.T., et al. (2014) Retention in Care Is More Strongly Associated with Viral Suppression in HIV-Infected Patients with Lower versus Higher CD4 Counts. JAIDS Journal of Acquired Immune Deficiency Syndromes, 65, 333-339. https://doi.org/10.1097/QAI.0000000000000023

[20] Dang, B.N., Westbrook, R.A., Hartman, C.M. and Giordano, T.P. (2016) Retaining HIV Patients in Care: The Role of Initial Patient Care Experiences. AIDS and Behavior, 20, 2477-2487. https://doi.org/10.1007/s10461-016-1340-y

[21] Dang, B.N., Westbrook, R.A., Njue, S.M. and Giordano, T.P. (2017) Building Trust and Rapport Early in the New Doctor-Patient Relationship: A Longitudinal Qualitative Study. BMC Medical Education, 17, 32. https://doi.org/10.1186/s12909-017-0868-5

[22] Monroe, A.K., Lau, B., Mugavero, M.J., Mathews, W.C., Mayer, K.H., Napravnik, S., et al. (2016) Heavy Alcohol Use Is Associated with Worse Retention in HIV Care. Journal of Acquired Immune Deficiency Syndromes, 73, 419-425. https://doi.org/10.1097/QAI.0000000000001083

[23] Sinha, R. (2001) How Does Stress Increase Risk of Drug Abuse and Relapse? Psychopharmacology, 158, 343-359. https://doi.org/10.1007/s002130100917

[24] Sinha, R. (2008) Chronic Stress, Drug Use, and Vulnerability to Addiction. Annals of the New York Academy of Sciences, 1141, 105-130. https://doi.org/10.1196/annals.1441.030

[25] Middeldorp, C.M., Cath, D.C., Beem, A.L., Willemsen, G. and Boomsma, D.I. (2008) Life Events, Anxious Depression and Personality: A Prospective and Genetic Study. Psychological Medicine, 38, 1557-1565. https://doi.org/10.1017/S0033291708002985

[26] Wichers, M., Geschwind, N., Jacobs, N., Kenis, G., Peeters, F., Derom, C., et al. (2009) Transition from Stress Sensitivity to a Depressive State: Longitudinal Twin Study. The British Journal of Psychiatry, 195, 498-503.

https://doi.org/10.1192/bjp.bp.108.056853 